\title{
CITRA PEREMPUAN DALAM CERITA RAKYAT KERAJAAN MURSALA LEGENDA PUTRI RUNDUK
}

\section{The Image of Women in The Royal Folklore of Mursala The Legnd of The Putri Runduk}

\author{
Tiflatul Husna ${ }^{a}$ dan Nurelide ${ }^{b}$ \\ ${ }^{a}$ Universitas Muslim Nusantara (UMN) Al Washliyah \\ Jalan Garu II A No. 93, Medan \\ bBalai Bahasa Sumatera Utara \\ Jalan Kolam Ujung No 7 Medan Estate \\ Pos-el: tiflatulhusna97@gmail.com \\ Pos-el: nurelide71@yahoo.com \\ tanggal naskah masuk 5 September 2018 \\ tanggal akhir penyuntingan 28 November 2018
}

\begin{abstract}
The aim of this study is to describe (1) the description of female characters, (2) the treatment received by female characters from male characters, and (3) the gender role of female characters in Mursala Kingdom folklore: the Legend of Putri Runduk. The object of this research is folklore. The data analysis technique used is descriptive. The data of study are as follow: (1) depiction of female figures in this study in terms of three aspects, namely physiological aspects, sociological aspects, and psychological aspects. (2) the treatment received by female leaders from male figures has an impact on the high or low level of female figures in the community's view. (3) gender roles in this study are divided into two, namely domestic and public roles.
\end{abstract}

Keywords: image of women, role of gender, folklore

\section{Abstrak}

Penelitian ini bertujuan untuk mendeskripsikan (1) penggambaran tokoh perempuan, (2) perlakuan yang diterima tokoh perempuan dari tokoh laki-laki, dan (3) peran gender tokoh perempuan dalam cerita rakyat Kerajaan Mursala: Legenda Putri Runduk. Objek penelitian berupa cerita rakyat. Pengumpulan data menggunakan teknik baca berulang-ulang dan pencatatan. Teknik analisis data bersifat deskriftif. Temuan penelitian (1) penggambaran tokoh perempuan ditinjau dari tiga aspek yaitu aspek fisiologis, aspek sosiologis, dan aspek psikologis. (2) perlakuan yang diterima tokoh perempuan dari tokoh laki-laki berdampak pada tinggi atau rendahnya tokoh perempuan dalam pandangan masyarakat. (3) peran gender dalam penelitian ini terbagi dua yaitu peran domestik dan publik.

Kata-kata kunci: citra perempuan, peran gender, cerita rakyat

\section{PENDAHULUAN}

Cerita rakyat adalah cerita dari mulut ke mulut yang merupakan karya tradisional yang lahir dari budaya masyarakat (Harvilahti, 2003:200). Seiring berjalan waktu, cerita rakyat yang diwariskan turun-temurun melalui lisan tersebut tentu mengalami perubahan baik dalam penambahan dan pengurangan cerita sehingga membentuk versinya masingmasing. Endraswara (2010:3) bahwa cerita rakyat diwariskan secara turun-temurun dari satu generasi ke generasi berikutnya dalam masyarakat tertentu. Tradisi lisan dalam cerita rakyat merupakan bagian dari folklor, yaitu folklor lisan. Menilik dari pengertian tersebut, jika dicermati 
pendapat itu benar adanya, karena semua tradisi lisan dalam cerita rakyat memang merupakan bagian dari folklor. Cerita rakyat Kerajaan Mursala: Legenda Putri Runduk misalnya, dianggap benar-benar terjadi oleh masyarakat sekitar. Legenda menurut Danandjaya (2002:66) adalah cerita prosa rakyat yang dianggap oleh empunya cerita sebagai suatu kejadian yang sungguh-sungguh terjadi.

Legenda Putri Runduk adalah cerita rakyat yang berasal dari daerah Tapanuli Tengah tepatnya kerajaan Mursala. Pulau Mursala terletak pada $1,7^{\circ}$ LU dan $98,5^{\circ}$ BT dan termasuk wilayah Kecamatan Tapian Nauli Kabupaten Tapanuli Tengah. Luas Pulau Mursala \pm $8.000 \mathrm{Ha}$, merupakan daerah perbukitan yang indah. Terdapat beberapa aliran sungai berbatu dengan aliran cukup deras yang mengalir membelah Pulau Mursala. Perairan Pulau Mursala dijadikan konservasi terumbu karang sedangkan Pulau Mursala berpeluang untuk dijadikan tempat wisata berburu dan resort. Jarak tempuh ke Pulau mursala dari Kota Pandan maupun Kota Sibolga dengan Speed Boat sekitar 60 menit. Beberapa gugus pulau pulau kecil disekitar Pulau Mursala seperti Pulau Silabu-labu Nagodang, Pulau Kalimantung Namenek, Pulau Jambe, dan Pulau Puti memiliki kekhasan tersendiri yang menambah keindahan wisata bahari Pulau Mursala. (http://budaya-indonesiasekarang.blogspot.com/2010/11/kabupaten -tapanuli-tengah-sumatera-utara.html).

Cerita rakyat ini memiliki banyak versi dengan berbagai sudut pandang penyampaian. Ada yang mengatakan bahwa Putri Runduk adalah anak Raja Linggom di Kerajaan Mursala yang disukai oleh Pangeran Abbessina namun ternyata Putri telah bertunangan dengan Pangeran Sorkam, Datuk Itam. Surat lamaran Pangeran Abbessina untuk Putri ditolak dan dibalas oleh Adofo seorang pelarian dari Abbesina. Saat itu Adofo adalah kepercayaan raja Linggom. Itulah cikal -bakal penyerangan yang dilakukan oleh Kerajaan Abbessina kepada Kerajaan Mursala lalu Kerajaan Sorkam memberikan bantuan dengan cara mengguncang tanah Mursala dan menariknya agar dekat dengan kerajaan Sorkam. Versi lain mengatakan, Putri Runduk hendak disunting oleh Raja Janggi dari Eropa. Putri Runduk meminta syarat agar Mursala didekatkan dengan Sorkam dan Raja Janggi menerima persyaratan itu dan harus selesai sebelum ayam berkokok. Ternyata, ayam terlalu cepat berkokok karena adanya alu yang dipukul oleh dayang istana. Pertempuran terjadi. Putri Runduk membawa bekal-bekal seperti setrika, nasi, dan lain-lain sehingga akhirnya tercecer lalu membentuk pulaupulau kecil.

Dalam penelitian ini, cerita rakyat Kerajaan Mursala: Legenda Putri Runduk objek studi sastra menganalisis citra perempuan. Unsur-unsur yang ingin diteliti adalah (1) penggambaran tokoh perempuan, (2) perlakuan yang diterima tokoh perempuan dari tokoh laki-laki, dan (3) peran gender tokoh perempuan. Penelitian ini menggunakan jenis penelitian pustaka sebab data primer dan data sekundernya bersumber dari pustaka, yaitu naskah tertulis.

Cerita rakyat Kerajaan Mursala: Legenda Putri Runduk yang dijadikan bahan penelitian ini bersumber dari salah satu naskah yang diikutkan dalam lomba penulisan cerita rakyat Sumatera Utara yang diadakan dan diterbitkan oleh Dinas Perpustakaan dan Arsip Provinsi Sumatera Utara Medan, dengan nama penulis Adi Putra.

\section{LANDASAN TEORI}

Legenda menurut Danandjaya (2002:66) adalah cerita prosa rakyat yang dianggap oleh empunya cerita sebagai suatu kejadian yang sungguh-sungguh terjadi.

Citra perempuan adalah pandangan-pandangan atau ide-ide tentang perempuan, bagaimana posisi dan 
perannya dalam masyarakat dan potensinya di tengah-tengah kekuasaan patriarki (Sugihastuti dan Siti 2007:46). Keterlibatan perempuan dalam lingkup publik selalu minim dikarenakan adanya kontruksi sosial yang dibentuk oleh masyarakat sehingga terjadi pembagian ruang gerak. Perempuan hanya terlibat dalam urusan rumah tangga dan jarang sekali tampil di ruang publik. Sebagaimana yang diungkapkan Arivia dalam Sari (2017:1-13) bahwa laki-laki sangat eksis dalam dunia sosial, bisnis, industri, dan juga di dalam keluarga sedangkan perempuan seringkali di dalam rumah.

Hal-hal tersebut mempengaruhi citra perempuan itu sendiri adalah budaya patriarki yang melekat dalam masyarakat sehingga terjadi ketidakadilan gender. Gender menurut Sugihastuti dan Siti (2007:72) merupakan sebuah sifat yang melekat pada kaum laki-laki maupun perempuan yang dikonstruksikan secara sosial maupun kultural.

Kajian terhadap citra perempuan dalam kesusatraan Indonesia dapat ditemukan dalam karya-karya puisi, drama, dan cerita rakyat. Bronner dalam Kanzunnudin (2015:6) menyatakan bahwa cerita rakyat merupakan cerminan sebuah realitas budaya (nilai, hubungan sosial, dan pandangan baru), perefleksian digunakan untuk menandakan yang dipertujukkan. Cerita rakyat Kerajaan Mursala: Legenda Putri Runduk adalah jenis cerita rakyat verbal. Sims dan Martine Stephens (2005:13-15) mengatakan bahwa jenis cerita rakyat verbal merupakan jenis cerita rakyat ini meliputi semua adat yang diwujudkan dalam kata, baik yang dituangkan dalam musik maupun bentuk kegiatan yang diekspresikan dalam kata atau frasa. Cerita rakyat yang termasuk jenis ini yakni nyanyian rakyat, mitos, dongeng, legenda, dan teka-teki.

Fungsi cerita rakyat menurut Atmazaki (2007:138) menyatakan bahwa fungsi cerita rakyat meliputi: (a) untuk mengekspresikan gejolak jiwa dan renungannya tentang kehidupan oleh masyarakat terdahulu, (b) untuk mengukuhkan solidaritas masyarakat, dan (c) digunakan untuk memuji raja, pemimpin, dan orang atau benda yang dianggap suci, keramat, atau berwibawa oleh kolektifnya.

\section{METODE PENELITIAN}

Desain penelitian ini adalah deskriptif kualitatif. Metode yang digunakan dalam penelitian ini adalah metode deskriptif dengan pendekatan kualitatif. Penelitian deskriptif kualitatif merupakan penelitian yang dimaksudkan untuk memberikan gambaran secara sistematis, faktual dan akurat mengenai data, sifat-sifat serta hubungan fenomena yang diteliti.

Sumber data penelitian ini adalah Cerita rakyat Kerajaan Mursala: Legenda Putri Runduk yang salah satu naskah yang diikutkan dalam lomba penulisan cerita rakyat Sumatera Utara yang diadakan dan diterbitkan oleh Dinas Perpustakaan dan Arsip Provinsi Sumatera Utara Medan, dengan nama penulis Adi Putra.

Dalam penelitian ini, penulis menggunakan analisis data kualitatif untuk menganalisis data cerita rakyat. Berdasarkan analisis data tersebut, peneliti mengikuti prosedur reduksi data, penyajian data, verifikasi data, dan penyimpulan data.

\section{PEMBAHASAN}

Berdasarkan cerita yang ditulis oleh Putra, diperoleh sudut pandang cerita sebagai berikut:

Raja Linggom adalah Raja di Kerajaan Mursala. Belum memiliki keturunan walau sudah seperempat abad usia pernikahan. Lalu, datanglah Adofo seorang pelarian dari Abbessina. Ia berjanji menolong raja memecahkan persoalan. Adofo ditemukan oleh Datuk Langit, elang kesayangan raja. Adofo terombang-ambing di lautan karena melarikan diri dari hukuman pancung. Ia 
telah melakukan kesalahan pada rajanya, Raja Dzigbode.

Menurut penerawangan Adofo, ada sihir hitam yang menghalangi kehamilan Permaisuri. Boneka mini hitam harus segera di temukan. Tidak lama, benda itu ditemukan oleh sepasang suami istri yang bekerja sebagai nelayan. Sebagai imbalan mereka dapat tinggal di istana. Istri dari nelayan itu ternyata sedang hamil. Jika anaknya lahir maka akan dijadikan saudara oleh anak raja kelak.

Tidak lama permaisuri pun hamil lalu lahirlah seorang anak perempuan. Raja menjadi sedih, sebab ia berharap anak yang lahir adalah seorang laki-laki. Namun ternyata seorang perempuan. Banyak tamu yang memuji kecantikannya sehingga terobati juga kekecewaan raja. Akhirnya, raja memberi nama anak perempuan itu dengan nama Putri Runduk.

Filosofi Runduk versi Raja sendiri adalah bahwa putrinya itu diharapkan kelak menjadi seorang yang memiliki wawasan luas namun tetap rendah hati, seperti padi. Semakin berisi semakin merunduk. Raja ingin, Putrinya akan menjadi pewaris kerajaan. Sehingga tidak boleh berlaku kasar dan egois pada rakyatnya. Putri Runduk tumbuh menjadi anak yang lincah, lucu, dan cerdas.

Putri Runduk telah remaja, kemampuan bela dirinya tidak diragukan lagi. Dengan parasnya yang rupawan ia menjadi sosok yang mengagumkan. Putri Runduk memiliki saudara atau dayang anak dari nelayan yang menemukan sihir itu. Dayang itu bernama Sikambang. Ia mengajak Sikambang pergi ke Sorkam untuk melihat pameran. Namun Sikambang menolak, sebaiknya minta izinlah pada Raja dan Permaisuri. Lalu mereka menemui permaisuri dan Putri Runduk menyampaikan niatnya. Tentu saja Raja tidak memberi izin. Sikap Putri Runduk yang serba ingin tahu membuat ia mengabaikan perkataan ayahnya. Dia tetap pergi bersama Sikambang dengan teknik penyamaran. Ia menyamar menjadi lakilaki begitu pun Sikambang. Perahu yang mereka gunakan adalah perahu buatan ayah Sikambang berdasarkan permintaan Putri.

Tibalah mereka di daratan Sorkam. Ternyata sedang ada pertandingan di sebuah arena laga. Putri Runduk dengan nama samaran Jogi dan Sikambang dengan panggilan Sihol. Mereka berhasil mengelabui para penonton di sana. Putri Runduk mendaftar menjadi peserta, Sikambang khawatir bukan main. Tiga kali laga, Putri berhasil memenangkan pertandingan. Putri lalu menanti orang yang maju untuk berikutnya. Beradu pandanglah Ia dengan seorang pemuda, berdesir hatinya. Pemuda itu bernama Datuk Itam, pangeran Sorkam. Pangeran Sorkam naik ke arena. Lalu memperkenalkan diri. Putri membalas perkenal itu dengan menyebutkan nama. Sayang, Putri lupa dengan penyamarannya. Ia menggunakan suara aslinya yang lemah lembut. Putri gugup, ia menyadari kekeliruannya. Lalu mengulang menyebutkan namanya dengan cara yang diberat-beratkan. Pangeran Sorkam membalikkan badan. Pertanda tak ingin meneruskan pertandingan. Dicegah oleh Putri. Kemudian Pangeran Sorkam mengungkapkan pikirannya bahwa ia tidak ingin berlaga dengan seorang perempuan. Terkejutlah para penonton. Takjub melihat kepiawaian laga perempuan itu. Putri mengolok-olok Pangeran Sorkam, meminta bukti. Buktikan! Buktikan! Katanya, diikuti sorak para penonton. Terpancing juga Pangeran Sorkam, ia melakukan gerakan membalikkan badan dan mengayunkan kaki. Terlepaslah penutup kepala Jogi alias Putri Runduk. Tergerai rambutnya.

Putri Runduk coba membalas perlakuan Pangeran Sorkam dengan cara melayangkan kaki ke arah wajah Pangeran namun refleks mengelak. Alhasil, Putri kehilangan keseimbangan. Pangeran Sorkam menangkap tubuh Putri yang 
limbung sehingga tidak jadi terjatuh. Dada kedua insan itu berdebar, saling jatuh cinta. Akhirnya mereka turun dari arena laga, tidak penting kalah atau menang. Pangeran Sorkam mengajak Putri berbincang.

Melihat itu, Datuk Langit mendekat ke arah Putri. Ia telah diutus oleh Raja Linggom karena khawatir tentang Putrinya yang lari dari istana. Ternyata Pangeran Sorkam mengenal Datuk Langit, sebab sering berkirim surat. Ayahnya merupakan Sahabat Raja Linggom. Sehingga ia mengajak Putri ke istana. Raja Linggom telah mengetahui keberadaan putrinya dan menyusul ke Sorkam.

Kejadian tersebut dilihat oleh pangeran Abbessina. Kebetulan ia sedang di situ. Ia terpesona dan merasa jatuh cinta dengan Putri Runduk. Ia yang telah lama menunggu jodoh merasa memiliki ketertarikan yang luar biasa dengan Putri. Dia pun menemui Putri yang sedang berbincang dengan Pangeran Sorkam dan meraih tangan Putri untuk berkenalan. Serta-merta ia mengajak Putri bersamanya. Tentu saja, Pangeran Sorkam kesal. Sehingga menarik tangan Putri untuk menjauh. Putri menurut saja. Pangeran Abbesina yang bernama Demessie marah besar.

Pangeran Sorkam melamar Putri Runduk. Tidak ada hambatan sebab ayah mereka adalah sahabat. Akan digelar pesta pernikahan. Namun, Pangeran Abbessina telah mengirimkan surat ke Mursala untuk melamar Putri. Raja memerintahkan untuk mengabaikan saja sebab ia akan menikahkan Putri dengan Datuk Itam, Pangeran Sorkam. Adofo sebagai pelarian dari Abbessina tahu adat di negerinya, penolakan itu adalah sebuah penghinaan. Terlebih surat itu dibalas oleh Adofo seorang pelarian. Dalam surat balasan itu, ia menawarkan kerja sama karena ia rupanya sangat merindukan kampung halamannya. Ia ingin pulang ke Abbessina.
Tanpa diduga, kerajaan Abbessina melalui perintah Pangeran Demessie melakukan penyerangan ke kerajaan Mursala. Mengetahui adanya pengkhianatan yang dilakukan oleh Adofo tanpa basa-basi, Putri langsung menghunuskan pedang ke dada Adofo. Putri ikut dalam pertempuran mempertaruhkan marwah Mursala. Permaisuri terbunuh begitu pun Raja. Tertinggal hanyalah Putri Runduk, Sikambang, dan Pangeran Demessie. Sebelumnya Datuk Langit telah mengabarkan kepada Pangeran Sorkam untuk membantu kerajaan Mursala. Dengan kekuatannya, Pangeran Sorkam menarik pulau Mursala mendekati daerah Sorkam. Tanah Mursala bergetar hebat, bergerak.

Saat terdesak, Putri Runduk diajak oleh Pangeran Demessie ke Abbessina jika ingin selamat. Putri Runduk terjebak. Ia tidak bisa berbuat apa-apa. Sikambang hanya bisa menangis menyaksikan dari jauh. Pedang Pangeran Demissie telah menari-nari di depan matanya. Saat itulah Datuk Langit datang dan mencakar Pangeran Demissie. Pangeran Demissie kesakitan. Sikambang mendekat, mengajak Putri Runduk lari namun ditolak. Baginya lebih baik mati. Tak ada lagi yang ingin dipertahankannya. Dia tidak punya apaapa lagi. Sikambang meyakinkan Putri bahwa masih ada dia sebagai saudara dan mereka akan bersama-sama membangun Mursala. Akhirnya bujukan Sikambang berhasil juga. Mereka pergi menjauh. Datuk Langit terus menyerang Pangeran Demessie.

Pergerakan tanah yang terjadi membuat pergeseran lokasi. Jalan biasa yang dilalui oleh Putri dan Sikambang banyak berubah. Sampai perjalanan mereka terjebak di ujung yaitu tepi tebing. Mereka pun beristirahat sambil memakan nasi yang telah dibungkuskan oleh Sikambang untuk Putri. Sikambang juga menunjukkan beberapa barang kesayangan milik Putri yang sempat diambilnya. Putri 
menangis. Ia tahu pergerakan tanah yang terjadi adalah karena kekasihnya, Pangeran Sorkam. Saat mereka beristirahat, entah bagaimana caranya Pangeran Demissie sudah ada di hadapan. Putri dan Sikambang yang sedang berpelukan terkejut. Pangeran itu tetap meminta Putri menjadi istrinya. Dengan seketika Putri berdiri dan meludah. Ia meloncat dari tebing. Sikambang histeris begitu pun Datuk Langit. Datuk Langit dengan kesetiaannya mencoba mencakar baju Putri agar dapat diangkat ke daratan lagi. Tubuh Putri melayang-layang di udara lalu tercebur ke air dan membentuk sebuah pulau.

Penggambaran tokoh perempuan dalam pembahasan ini mengacu pada tiga aspek yaitu aspek fisiologis, aspek sosiologis, dan aspek psikologis.

Aspek fisiologis meliputi usia, jenis kelamin, keadaan tubuh, dan ciri-ciri muka, dan sebagainya. Dimensi sosiologis meliputi status sosial, pekerjaan, jabatan, peranan di dalam masyarakat, pendidikan, agama, pekerjaan, jabatan, pandangan hidup, ideologi, aktivitas sosial, organisasi, hobi, bangsa, suku, dan keturunan. Dimensi psikologis meliputi mentalitas, ukuran moral, keinginan dan perasaan pribadi, sikap dan kelakuan, juga intelektualitas (Wiyatmi, 2012:30-31).

\section{Penggambaran Tokoh Perempuan dalam Cerita Rakyat Kerajaan Mursala: Legenda Putri Runduk}

\section{Aspek Fisiologis}

Kehadiran seorang anak dalam sebuah rumah tangga adalah hal yang sangat penting untuk merekatkan hubungan suami-istri. Begitu pun di Kerajaan Mursala. Namun, anak yang diinginkan selalu berjenis kelamin laki-laki khususnya anak pertama. Kontruksi sosial membentuk opini masyarakat bahwa anak laki-laki lebih bernilai dibandingkan anak perempuan. Anak laki-laki dianggap lebih mampu menjaga dan mengawal muruah keluarga.
Demikian pula di daerah Tapanuli, jika anak pertama, kedua, ketiga berjenis kelamin perempuan maka akan terus dilakukan upaya agar memperoleh keturunan laki-laki. Anak laki-laki lah yang dianggap sebagai pewaris keturunan (suku/marga).

Putri Raja Linggom yang berjenis kelamin perempuan nyatanya mampu meluluhkan hati Raja sebab banyaknya puji-pujian yang diberikan karena kecantikannya. Adapun gambaran fisiologisnya sebagai berikut:

1. Cantik

Dalam cerita rakyat Kerajaan Mursala: Legenda Putri Runduk terdapat tokoh perempuan bernama Runduk. Runduk adalah putri dari Raja Linggom, Raja dari kerajaan Mursala. Ia memiliki wajah yang cantik dan bercahaya. Semula kehadiran Runduk yang telah dinantikan selama seperempat abad tidak menyenangkan raja sebab ia ingin anak laki-laki. Akan tetapi ketika banyak tamu dari belahan negeri memuji-muji kecantikan dan wajah putri yang bersinar indah timbullah rasa kagum dan suka cita di dalam hati Raja. Hal ini dapat dilihat dalam beberapa kutipan berikut ini:

"Diakah yang kurindukan selama ini? Wajah putrinya seperti bercahaya. Raja mengelus pipi sang bayi dengan telunjuknya. Sang bayi menggerakkan kepala dengan mulut mengerucut seperti sedang menyusu. Raja tersenyum melihat reaksi lucu bayinya" (Putra, 2017:36).

Dalam beberapa percakapan keadaan tentang kecantikan sang Putri terekam sebagai berikut, (Putra, 2017:3637) "Aduhai, sungguh paras seorang dewi”, "Aku selalu mengagumi cahaya purnama, tapi siapa sangka kekagumanku berpindah padanya", "Kecantikan ratu Cleopatra bahkan tidak ada apa-apanya."

2. Berambut Hitam

Putri Runduk dalam cerita ini digambarkan memiliki rambut hitam yang 
terurai panjang. Terlihat dalam penjabaran berikut ini.

"Putri Runduk merasakan sambaran angin menerpa wajahnya. Sambaran angin menyebabkkan penutup kepalanya terlepas. Rambut hitam panjangnya jatuh tergerai lembut. Topeng berkumis yang terbuat dari karet tipis ikut pula terlepas, memperlihatkan wajah cantiknya" (Putra, 2017: 83).

\section{Aspek Sosiologis}

Hampir 50\% Suku Indonesia dan Luar negeri ada di Tapanuli Tengah. Mayoritas penduduknya adalah Suku Batak/Batak Toba dan Mandailing. (Wikipedia). Suku di Tapanuli Tengah multi etnik yaitu suku Batak, Minang, Jawa - Madura, Bugis, Cina, Aceh, Melayu, Sunda, dan lain-lainKerukunan, keamanan, ketertiban dan toleransi dalam semangat gotong-royong yang terjalin dan terbina selama ini membuat Tapanuli Tengah semakin kondusif dan tangguh secara sosial kemasyarakatan dalam menyikapi globalisasi dengan berbagai perubahan yang begitu cepat. Dalam kisah ini Putri Runduk secara sosiologis dijabarkan seperti berikut ini:

\section{Keturunan Raja}

Putri Runduk adalah Putri Raja Linggom di kerajaan Mursala. Putri Runduk akan menjadi pewaris tunggal kerajaan. Hal ini ditemukan dalam kutipan berikut:

"Kebahagiaan mereka terasa lengkap. Raja tak merisaukan lagi jika kelak menyerahkan tahtanya kepada sang putri. Ia yakin saat dewasa nanti putrinya mampu menanggung beban itu" (Putra, 2017: 40).

\section{Tinggal di Lingkungan Istana}

Putri Runduk tinggal di lingkungan istana, terlihat dalam kutipan berikut:

"Keesokan harinya, Raja membawa Putri Runduk ke halaman depan istana...." (Putra, 2017: 53).

\section{Aspek Psikologis}

Dijelaskan bahwa kebanyakan penduduk yang tinggal di Tapanuli Tengah adalah suku Batak. Sehingga, apa yang menjadi perilaku tokoh perempuan dan laki-laki dipengaruhi oleh lingkungan tempat tinggal atau masyarakat pembentuknya. Secara umum, masyarakat Batak memiliki prinsip hidup yang kuat dan kokoh. Beberapa di antaranya adalah masyarakat suku Batak tidak mengenal malu dalam menjalan apapun bentuk usaha yang dilakoninya yang penting halal. Maka tidak jarang ditemukan anak-anak mengutip butut di acara pernikahan dan mengambil sisa makanan untuk diberikan kepada hewan peliharaan. Selain itu, sikap setia kawan tidak perlu diragukan selagi tidak ada perlakuan curang antara satu sama lain sehingga dikenal istilah hancur demi kawan. Selain itu, orang Batak terkenal dengan logat bicaranya yang terdengar kasar dan keras atau lebih tepatnya tegas. Namun, di balik itu semua hati orang Batak biasanya lembut dan mudah memberi atau menolong orang lain. Sebab, memberi bagi mereka adalah kekayaan tersendiri.

Bagi mereka, kekayaan bukanlah soal materi semata-mata. Sifat pantang menyerah juga merupakan prinsip yang tidak dapat ditawar. Orang-orang Batak yang pergi merantau tidak akan pulang kampung sebelum berhasil. Istilah "biar kambing di kampung sendiri tapi banteng di perantauan" menjadi kalimat pegangan yang cukup bombastis dalam memotivasi. Demikian pula dalam kisah Putri Runduk, beberapa aspek dipandang dari psikologis diuraikan seperti berikut ini:

1. Patuh

Putri Runduk selaku tokoh perempuan dalam cerita ini memiliki beberapa sifat dan karakter salah satunya adalah sikap patuh pada orang tua. Dia patuh mengikuti pelajaran dari ayah dan ibunya sehingga mampu melakukan kedua ajaran berbeda itu dengan sama baik. 
Pernyataan ini didukung oleh penggalan berikut:

Tahun demi tahun berlalu dengan cepat. Putri Runduk tumbuh menjadi putri yang sangat cantik, anggun dalam tata krama dan pergaulan serta gesit dalam laga. Putri Runduk mampu mengalahkan sepuluh prajurit yang menyerang dalam latihan. Meskipun begitu, kegagahannya dalam latihan laga, tidak mengurangi kegemulaiannya dalam tarian. Bahkan Sikambang, putri dari ibu asuh Putri Runduk (pasangan nelayan) yang menjadi dayangnya tak bosan memberikan pujian" (Putra, 2017:58).

\section{Rendah hati}

Putri Runduk memiliki sifat rendah hati. Dia tidak mau dipanggil Tuan oleh Sikambang. Dia mau dipanggil dengan nama saja, yaitu Runduk. Ini mencerminkan tidak adanya perbedaan kasta sosial di antara mereka.

"Sudah berapa kali kukatakan padamu, panggil saja aku Runduk. Sela Putri Runduk. Baginya Sikambang tidak hanya sebagai dayang, tapi lebih dari itu. Ia sudah menganggap Sikambang sebagai sahabat, bahkan sudah seperti kakaknya sendiri” (Putra, 2017:59).

\section{Pantang Menyerah}

Raja dan Permaisuri tidak memberi izin kepada Putri Runduk untuk melihat Pekan Raya di Sorkam. Rasa penasaran yang tinggi membuat Putri Runduk memiliki semangat pantang menyerah untuk mewujudkan impiannya.

"Sekali melangkah maju, pantang bagiku mundur," (Putra, 2017:63). Putri Runduk tetap pergi dengan menggunakan teknik penyamaran.

\section{Gesit}

Selain cantik, Putri Runduk juga digambarkan sebagai tokoh yang gagah dan gesit namun mampu menjadi sosok yang lemah gemulai dalam kondisi tertentu. Terlihat dalam kutipan berikut:
Tahun demi tahun berlalu dengan cepat. Putri Runduk tumbuh menjadi putri yang sangat cantik, anggun dalam tata krama dan pergaulan serta gesit dalam laga. Putri Runduk mampu mengalahkan sepuluh prajurit yang menyerang dalam latihan. Meskipun begitu, kegagahannya dalam latihan laga, tidak mengurangi kegemulaiannya dalam tarian. Bahkan Sikambang, putri dari ibu asuh Putri Runduk (pasangan nelayan) yang menjadi dayangnya tak bosan memberikan pujian" (Putra, 2017:58).

\section{Kreatif dan Cerdas}

Untuk mewujudkan harapannya dapat pergi ke Sorkam, Putri Runduk melakukan penyamaran sebagai seorang lelaki. Sehingga orang-orang tidak mengenalnya dan suaranya diberatberatkan, demikian juga Sikambang. Padahal, hal ini belum pernah diajarkan oleh raja dan pihak istana kepada Putri Runduk.

"Jangan panggil aku Runduk. Potong Putri dengan suara diberatberatkan. Saat ini kau dan aku adalah seorang pria. Dan suaramu itu... berapa kali kukatakan kau harus memberatberatkan suaramu seperti pria. Saat ini aku adalah Jogi dan kau Sihol. Ingat itu" (Putra, 2017:68).

\section{Menyukai Tantangan}

Putri Runduk tidak membedakan antara laki-laki dan perempuan. Ketika sampai di Sorkam ada laga sesama lelaki dia pun ingin ikut naik ke arena laga karena posisinya saat itu adalah seorang lelaki meski dalam penyamaran.

"Ini kesempatan menjajal kemampuan tarungku. Apa salahnya jika aku ikut serta?" (Putra, 2017:71).

\section{Berani}

Putri Runduk memiliki sifat yang berani. Terlihat ketika ia ingin ikut bertempur saat kerajaan Mursala diserang oleh Kerajaan Abbessina. 
"Aku juga akan ikut bertempur di sisi Ayah" (Putra, 2017:110).

\section{Tegas}

Saat Putri Runduk mengetahui adanya pengkhianatan yang dilakukan oleh Adofo, seorang pelarian dari Abbesina sehingga menyebabkan Mursala diserang oleh kerajaan tersebut. Maka dengan ketangkasannya Putri Runduk langsung mengambil sebuah keputusan yaitu membunuh Adofo.

"Atas nama kerajaan Mursala, aku, Runduk putri Linggom menjatuhkan hukuman mati kepada Adofo, pelarian dari Abbessina. Ucap Putri Runduk sesuai peraturan kerajaan Mursala dalam menjatuhkan hukuman kepada pengkhianat. Lalu dalam sekali tebas, nyawa Adofo melayang" (Putra, 2017:117).

\section{Perlakuan yang Diterima Tokoh Perempuan dari Tokoh Laki-laki dalam Cerita Rakyat Kerajaan Mursala Legenda Putri Runduk}

Raja sebagai tokoh laki-laki dalam cerita ini tidak memandang klasifikasi jenis kelamin. Ia memandang Putri Runduk sama seperti laki-laki untuk hal pertahanan diri. Tidak ada diskriminasi atau streotip yang dilakukan kepada Putri Runduk. Biasanya perempuan selalu berperan dalam ruang domestik namun raja ingin melibatkan putrinya dalam konteks publik. Ia berbeda pendapat dengan istrinya sebab sang permaisuri ingin Putri Runduk menerima pelajaran domestik seperti menjahit, menenun, memasak, bersolek, menari, dan hal umum yang dilakukan oleh kaum perempuan. Hingga pada akhirnya Putri Runduk memperoleh kedua pembelajaran itu dari ayah dan ibunya. Sehingga dapat disimpulkan bahwa posisi Putri Runduk ditinggikan oleh Raja selaku tokoh lakilaki. berikut:
"Sementara aku menginginkan Putri Runduk menjadi putri yang tangguh. Jika terjadi perang di daratan Suwarnadwipa dan tanah Jawa, lalu merembet kemana-mana, aku ingin putriku siap menghadapi serangan musuh" (Putra, 2017:47).

\section{Peran Gender Tokoh Perempuan}

Putri Runduk dalam cerita ini dikisahkan memperoleh pembelajaran bersifat domestik dari ibunya dan pembelajaran publik dari ayahnya. Namun dalam cerita ini Putri Runduk lebih banyak berperan dalam ranah publik. Seperti kutipan berikut ini.

"Aku takkan membiarkan ayah berjuang sendirian. Dan masalah ini bukan menjadi masalah ayah saja, tetapi sudah menjadi masalahku. Dikarenakan diriku mereka datang menyerang. Kata Putri Runduk. Raja tidak mengiyakan dan tidak pula menolak" (Putra, 2017:113).

Putri Runduk terlibat dalam pertempuran melawan Kerajaan Abbessina. Raja secara tidak langsung menyetujui permintaan putrinya itu.

"Serang dia terus, Runduk" seru Raja Linggom mengabaikan ucapan Pangeran Demessie yang tidak dimengertinya. (Putra, 2017:126).

\section{PENUTUP}

Berdasarkan pembahasan Citra Perempuan dalam Cerita Rakyat Kerajaan Mursala Legenda Putri Runduk di atas, dapat diambil beberapa simpulan, yaitu:

1. Penggambaran tokoh perempuan dalam penelitian ini dilihat dari tiga aspek yaitu: aspek fisiologi, psikologi, dan sosiologi. Secara aspek fisiologis, tokoh perempuan bernama Putri Runduk adalah gadis yang cantik, memiliki rambut panjang menghitam. Dilihat dari aspek psikologis, Putri Runduk adalah seorang keturunan Raja dan tinggal serta dibesarkan di lingkungan istana. Ditinjau dari aspek sosiologis tokoh Putri Runduk adalah 
seorang yang patuh, rendah hati, pantang menyerah, gesit, cerdas, kreatif, menyukai tantangan, tegas, dan berani.

2. Perlakuan yang diterima tokoh perempuan dari tokoh laki-laki berdampak pada tinggi atau rendahnya tokoh perempuan dalam pandangan masyarakat. Dalam penelitian ini kedudukan tokoh perempuan tidak mendapatkan perlakuan stereotip karena Putri Runduk adalah pewaris tahta kerajaan yang harus dibekali ilmu untuk bertempur mempertahankan kerajaan di samping tetap harus memperoleh pembelajaran yang bersifat domestik.

3. Peran gender dalam penelitian ini terbagi dua yaitu peran domestik dan publik. Tokoh perempuan dalam penelitian ini berperan dalam kedua bidang itu akan tetapi digambarkan lebih dominan dalam ruang publik.

\section{DAFTAR PUSTAKA}

Atmazaki. (2007). Ilmu Sastra: Teori dan Terapan. Padang: UNP Press.

Danandjaya, James. (2002). Folklor Indonesia, Ilmu Gosip, Dongeng, dan Lain-lain. Jakarta: Grafiti.

Endraswara, Suwardi. (2003). Metodologi Penelitian Sastra. Yogyakarta: Pustaka Widyatama.

Harvilahti, Lauri. (2003). Folklore and Oral Tradition. Helsinki: Finnish Literature Society.

http://budaya-indonesiasekarang.blogspot.com $/ 2010 / 11 / \mathrm{k}$ abupaten-tapanuli-tengah-

sumatera-utara.html (tersedia. Diakses November 2018)
https://id.wikipedia.org/wiki/Pulau_Mursal a (tersedia, Diakses November 2018).

Kanzunnudin, Mohammad. Mei 2015. Cerita Rakyat sebagai Sumber Kearifan

Lokal.https://www.researchgate.n et/publication/321003686_Cerita Rakyat_Sebagai_Sumber_Kearifa n_Lokal diakses tanggal 27 September 2018.

Putra, Adi. (2017). Kerajaan Mursala: Legenda Putri Runduk. Medan: Dinas Perpustakaan dan Arsip Provinsi Sumatera Utara.

Sari, Sartika. Juni 2017. Gagasan Kesetaraan Gender dalam Puisi di Sumatera Utara Tahun 1929: Kajian New Historicsm. Balai Bahasa Sumatera Utara. 15(1), Juni 2017.

Sims, Martha C. \& Martine Stephens. (2005). Living Folklore: An Introduction to the Study of People and Their Traditions. Logan Utah: Utah State University Press.

Sugihastuti, dan Siti, Hariti Sastriyani. (2007). Glosarium Seks dan Gender. Yogyakarta: Carasvati Books.

Wiyatmi. (2012). Kritik Sastra Feminis Teori dan Aplikasinya dalam Sastra Indonesia. Yogyakarta: Penerbit Ombak. 